\title{
REPENSAR A ESCALA COMO UMA CATEGORIA GEOGRÁFICA: DA ANÁLISE PARA A PRÁTICA*
}

\author{
Adam Moore* \\ Universidade da Califórnia
}

Resumo: Nas últimas duas décadas, os geógrafos humanos teorizaram fortemente a escala, e intensificaram as afirmações de que ela é um elemento fundamental da teoria geográfica. No entanto, concomitante a este movimento há uma preocupação crescente de que a escala tenha se tornado um conceito pesado, carregado com significados múltiplos, contraditórios e problemáticos. Eu partilho dessa inquietação e argumento que um debate semelhante sobre a utilidade da "identidade" como uma categoria conceitual nas ciências sociais oferece insights instrutivos. Em paralelo às críticas recentes de categorias de identidade como nação e raça, eu encaro a confusão conceitual em torno da escala - e da política de escala -, em parte, como consequência do fracasso em se distinguir claramente entre a escala como uma categoria de prática e uma categoria de análise. Ao adotar a escala como uma categoria de análise, os geógrafos tendem a reificá-la como uma entidade ontológica fundamental; assim, trata-se uma categoria social empregada na prática da política socioespacial como um instrumento teórico central. Defendo que esta manobra analítica não é nem útil nem necessária, e sintetizo suas consequências nas análises sobre política de escala. Por fim, esboço os contornos de um programa de pesquisa para as políticas de escala que leva essa injunção a sério - tanto em termos de como teorizar a escala como uma categoria da prática quanto no que diz respeito ao foco da pesquisa em política de escala.

Palavras-chave: categorias, epistemologia, prática, processo, escala.

\section{RETHINKING SCALE AS A GEOGRAPHICAL CATEGORY: FROM ANALYSIS TO PRACTICE}

Abstract: In the past two decades human geographers have intensely theorized scale, and extended claims that it is a foundational element of geographic theory. Yet attendant with this move has been a growing concern that scale has become an unwieldy concept laden with multiple, contradictory and problematic meanings. I share that concern, and argue that a similar debate about the usefulness of 'identity' as a conceptual category in social science offers instructive insights. Paralleling recent critiques of identity categories such as nation and race, I view the conceptual confusion surrounding scale - and scale politics - as, in part, the consequence of failing to make a clear distinction between scale as a category of practice and category of analysis. In adopting scale as a category of analysis geographers tend to reify it as a fundamental ontological entity, thereby treating a social category employed in the practice of sociospatial politics as a central theoretical tool. I argue that this analytical manoeuvre is neither helpful nor necessary, and outline its consequences in analyses of the politics of scale. Finally, I sketch the altered contours of a research programme for the politics of scale if we take this injunction seriously - both in terms of how we theorize scale as a category of practice and what becomes the focus of scale politics research.

Keywords: Categories, epistemology, practice, process, scale.

\section{REPENSAR LA ESCALA COMO UNA CATEGORÍA GEOGRÁFICA: DEL ANÁLISIS A LA PRÁCTICA}

Resumen: En las últimas dos décadas, los geógrafos humanos teorizaron fuertemente la escala, e intensificaron las afirmaciones de que es un elemento fundamental de la teoría geográfica. Sin embargo, con este movimiento, existe una preocupación creciente de que la escala se haya convertido en un concepto pesado, cargado con significados múltiples, contradictorios y problemáticos. Yo comparto esta inquietud y argumento que un debate similar sobre la utilidad de la "identidad" como una categoría conceptual en las ciencias sociales ofrece insights instructivos. En paralelo a las críticas recientes de las categorías de identidad como nación y raza, considero la confusión conceptual en torno a la escala -y la política de escala- en parte como consecuencia del fracaso en distinguirse claramente entre la escala como una categ oría de la práctica y una categoría de análisis. Al adoptar la escala como una categoría de análisis, los geógrafos tienden a reificarla como una entidad ontológica fundamental; así, se trata de una categoría social empleada en la práctica de la política socioespacial como un instrumento teórico central. Defiendo que esta maniobra analítica no es ni útil ni necesaria, y sintetiza sus consecuencias en los análisis sobre política de escala. Por último, esbozo los contornos de un programa de investigación para las políticas de escala que lleva este requerimiento en serio - tanto en términos de cómo teorizar la escala como una categoría de la práctica como en lo que se refiere al foco de la investigación en política de escala.

Palabras clave: Categorías, epistemología, práctica, proceso, escala.

*Traduzido do original: MOORE, Adam. Rethinking scale as a geographical category: from analysis to practice. Progress in Human Geography, 2008, vol. 32, n. 2, p. 203-225. Tradução: Sueli Vasconcelos. Revisão técnica: Rogério Haesbaert (UFF) e Daniel Sanfelici (UFF). A revista GEOgraphia agradece ao autor pela permissão para tradução e publicação do artigo.

*Doutor em Geografia. Professor do Departamento de Geografia da universidade da Califórnia - Los Angeles. Endereço: 1255 Bunche Hall, Los Angeles, CA, 90095. E-mail: adam.moore@geog.ucla.edu 
Introdução

A discussão sobre a escala na cultura popular explodiu nos últimos anos, alimentada por uma enxurrada de observações sobre o mundo cada vez mais "globalizado" em que vivemos. De acordo com essa metanarrativa, os avanços tecnológicos como a internet, os aviões a jato, as telecomunicações sem fio e a televisão por satélite estão encolhendo o mundo em uma "aldeia global". Por sua vez, diz-se que as comunidades e tradições locais são empurradas para um fluxo global de capital, ideias e pessoas, que são forçadas a confrontar (FRIEDMAN, 2000). As questões ambientais, como as mudanças climáticas, a poluição da água ou o desmatamento, são também cada vez mais enquadradas por ativistas políticos como preocupações globais que exigem normas e regulamentações internacionais (CASTREE, 2004). A escala tornou-se também um componente central de muitas formas de política de identidade: movimentos locais muitas vezes defendem um reescalonamento da governança, ao exigir mais autonomia local ou regional dos Estados-nação (SILVERN, 1999); alternativamente, houve um aumento da discussão sobre a "diáspora" por Estados que têm interesses econômicos ou políticos em cultivar laços com "sua" diáspora transnacional (BRUBAKER, 2005). Os cientistas sociais tornaramse também mais interessados em questões de escala. Teóricos políticos saudaram o potencial de uma futura estrutura de governança global e, ecoando os esforços da teoria da modernização das décadas de 1950 e 1960, houve muitas especulações equiparando processos globalizantes com a mudança de escala [scaling up] do espaço: isto é, o fim próximo do Estado-nação; a emergência de conflito ao longo das grandes linhas civilizacionais; ou uma penetração cada vez mais global do consumismo capitalista, que apaga comunidades e culturas tradicionais (BARBER, 1995; HELD, 1995; OHMAE, 1995; HUNTINGTON, 1996).

O crescente compromisso da geografia humana com a escala reflete desenvolvimentos na cultura popular e nas ciências sociais. Rejeitando as premissas mais estranhas encontradas na literatura da globalização, os geógrafos, no entanto, também falam de um mundo fluido e mutável de relações espaciais e, consequentemente, desenvolveram um interesse maior em processos de criação de escalas, no reescalonamento [rescaling] e nas políticas de escala. 0 primeiro grupo de geógrafos a assumir as questões teóricas de escala e política de escala emergiu da tradição político-econômica da geografia influenciada por Marx. Na década de 1970, eles começaram a analisar a forma como as forças do capitalismo modelavam e remodelavam o espaço na era pós-fordista, e em particular o papel da produção de escalas na facilitação desses processos. Antes disso, a escala era tratada principalmente como espaço inerte, abstrato, e as questões centrais de escala para geógrafos humanos eram operacionais e metodológicas - identificar os níveis espaciais em que os processos especificados operavam e determinar os níveis ótimos de pesquisa (McMASTER; SHEPPARD, 2004). Nas últimas duas décadas, porém, a escala assumiu aos poucos uma importância teórica cada vez maior na visão dos geógrafos: chega-se ao ponto de reivindicar a escala como um dos "conceitos fundamentais" da geografia (HOWITT, 1998).

Estas pesquisas recentes acerca da escala geraram uma maior valorização do aspecto inerentemente espacial da política, assim como suscitaram um conjunto cada vez mais diversificado - e muitas vezes contraditório - de entendimentos sobre as definições e propriedades fundamentais das escalas e sobre o que constitui as políticas de escala. Esta literatura foi revista em profundidade em outros textos (MARTSON, 2000; HERODES; WRIGHT, 2002; HOWITT, 2003; MCMASTER; SHEPPARD, 2004;. MARSTON et al, 2005), então farei uma pausa para destacar algumas posições importantes antes de prosseguir.

Possivelmente, o único ponto sobre o qual os geógrafos estão de acordo é que a escala não é uma categoria fixa ou determinada; pelo contrário, trata-se de um constructo social, fluido e contingente (MARSTON, 2000). No entanto, como acontece com outros conceitos analíticos, esse aceno para o construtivismo social agora quase ritual tende a obscurecer, ao invés de iluminar, diferentes abordagens teóricas para a escala. Quanto ao primeiro ponto de discussão, a definição e os atributos da escala, é possível identificar duas correntes de pensamento difusas, mas discerníveis que, em linhas gerais, se alinham ao longo de um espectro materialistaidealista. A primeira, e mais comum, é promulgada por geógrafos político-econômicos que tendem a ver as escalas como entidades socioespaciais materiais: Neil Smith descreve-os como a "materialização das forças sociais contestadas" (1993, p. 101) e "plataformas para tipos específicos de atividade social [...] plataformas de espaço absoluto em um mar mais amplo de espaço relacional" (2000, p. 725); Swyngedouw (1997a, p. 169) define escala como a "condensação das relações sociais de empoderamento e desempoderamento e da arena através da qual e na qual operam". Segundo esse ponto de vista, as escalas não são heurísticas geográficas independentes, mas correspondem a processos materiais reais, eventos e formações espaciais.

De modo alternativo, a escala tem sido caracterizada 
como uma "figura representacional" (JONES, 1998, p. 27) ou quadro discursivo (KURTZ, 2003). Deste ponto de vista, a escala é fundamentalmente um constructo epistemológico que apresenta ordenamentos socioespaciais específicos. Assim, diferentemente da abordagem político-econômica, não há correspondência necessária entre representações de escala pretendidas e as condições materiais. Entretanto, através da sua utilização e da contestação social que suscitam, as representações escalares podem, por sua vez, ter efeitos materiais. Por isso, Delaney e Leitner (1997, p. 94-95, 97) argumentam que a escala "não é simplesmente um fato externo aguardando descoberta, mas uma maneira de enquadrar concepções de realidade", e é através da "fusão de ideologias e práticas [escalares]" que as construções políticas de escala emergem.

As políticas de escala também têm sido uma área de teorização vibrante, mas controversa. A literatura da economia política postulou o modelo hierárquico (agrupado de modo variado) de escalas que vê a produção, a dissolução e a reprodução de "ajustes escalares" (scalar fixes) como condicionados por forças do capitalismo e pelo processo de acumulação de capital (HARVEY, 1982; TAYLOR, 1982; SWYNGEDOUW, 1992a; SMITH, 1995; BRENNER, 1997; 1998). Essas hierarquias de escala são combatidas pelo "salto de escalas" (jumping scales) ou pela criação de "alianças escalares" (scaled alliances) que escapam das soluções escalares repressivas (SMITH, 1993; SWYNGEDOUW, 2000). Howitt (1998) respondeu que as escalas não devem ser concebidas como níveis ou plataformas hierárquicas isoladas, mas devem ser definidas e politicamente contestadas sempre na relação de uma com a outra, como em uma escala musical. Marston (2000), por sua vez, criticou o foco restrito na produção capitalista, argumentando que as forças de reprodução social e consumo - em particular, no nível familiar também são cúmplices na construção e na reformulação das escalas. Recentemente, os geógrafos introduziram teorias de rede à política da escala (AMIN, 2002; LEITNER et al., 2002; LEITNER, 2004; BULKENEY, 2005), numa tentativa de entender melhor as intersecções, no âmbito da política espacial, entre as relações socioespaciais verticais e horizontais. Em suma, o tratamento dado pelos geógrafos à escala e à política da escala é quase tão múltiplo, fluido e contingente quanto as formas como o conceito em si é retratado.

\section{Deslizamentos conceituais da escala}

À luz dessas descrições variadas e controversas, vários geógrafos têm manifestado preocupação com o fato de a escala ter se tornado um termo carregado com uma ampla bagagem conceitual que é cada vez mais utilizada de uma maneira descuidada e analiticamente imprecisa, tendo sido questionado até mesmo o seu valor teórico. Vale a pena rever três críticas em particular. A primeira é a afirmação de Andrew Jonas (1994) de que os geógrafos tendem a confundir conceitos de escala abstratos e metafóricos. Por um lado, as categorias de escala como "local", "urbana" ou "global" são muitas vezes utilizadas de forma naturalizada, abstrações que não sofrem nenhum "trabalho" analítico. As escalas nesse sentido são dados não problematizados, fixos, que "são vistos como coisas em si mesmas a serem tratadas categoricamente" (HOWITT, 1998, p. 50). Por outro lado, os geógrafos recorrem a um rico vocabulário de representações metafóricas de escala para caracterizar políticas socioespaciais: "local" pode ser empregado para descrever as comunidades tradicionais impactadas pela globalização ou que resistem a ela (SWYNGEDOUW, 2004); bonecas russas (matrioska) podem ser usadas como referência para destacar a natureza "encaixada" das hierarquias de escala (HERODES; WRIGHT, 2002); e escadas e andaimes podem ser invocados para retratar as estruturas hierárquicas de escala que sustentam o capitalismo (BRENNER, 1999).

Enquanto essa tensão entre fixidez e fluidez na conceituação de escala é inevitável - e muitas vezes favorável a uma teorização mais imaginativa - muito frequentemente os usos abstratos e metafóricos da escala por geógrafos são mesclados sem reflexão, o que leva a uma confusão analítica. Por exemplo, em estudos urbanos a palavra "urbano" não se restringe a delimitar uma escala específica em que a pesquisa é conduzida; ela também serve, muitas vezes, como um atalho espacial-conceitual para processos sociais específicos (JONES, 1994, p. 259-60). O perigo nisso, como observou Agnew (1993, p. 258, grifo do autor), é que "pode-se começar a usar conceitos espaciais como abreviação de processos sociológicos complexos e escorregar facilmente para a substituição dos argumentos mais complexos pelos conceitos espaciais". Isso resulta em uma forma de "fetichismo espacial" (SAYER, 1985) que atribui ao próprio espaço - e, por extensão, aos rótulos analíticos de escala que aplicamos ao(s) espaço(s) eficácia causal.

A segunda crítica é oferecida por Neil Brenner (2001). Ele argumenta que a escala sofre de "enfraquecimento analítico" por causa da sua extensão excessiva e da 
mistura do termo com outros conceitos geográficos. Em particular, os geógrafos têm uma tendência a se referirem a escalas quando na verdade estão falando de arenas, locais, territórios ou localidades socioespaciais específicas. Quando essas unidades espaciais são classificadas sob a rubrica da escala, a noção de uma "política de escala" assume um significado singular que "denota a produção, a reconfiguração ou a contestação de algum aspecto da organização socioespacial dentro de uma arena geográfica relativamente limitada geralmente rotulada como local, urbana, regional, nacional, e assim por diante" (BRENNER, 2001, p. 599, grifo do autor).

Esta é uma extensão problemática do vocabulário escalar em dois aspectos principais. Primeiro, porque gera pressupostos teóricos a priori acerca daquilo que são, na verdade, questões empíricas abertas, ou seja: "a mera existência de organização escalar não resulta, ipso facto, em efeitos de escala sociologicamente ou politicamente relevantes" (BRENNER, 2001, p. 601, grifo do autor). Em segundo lugar porque, ao enquadrarem a sua investigação em termos escalares, em vez de nas arenas específicas socioespaciais que estão investigando, os geógrafos estão revisitando sem reflexão argumentos anteriores gerados por uma tradição de pesquisa rica e bem estabelecida sobre a produção do espaço via processos de produção do lugar [place-making], localização [localization] e territorialização. Além disso, essa compreensão singular das políticas de escala gera um deslizamento conceitual, haja vista que não está claramente separada de um segundo significado, plural, que destaca uma variedade de políticas espaciais, bem como ordenamentos e reordenamentos hierárquicos entre as escalas. Brenner afirma que esse conceito plural da política de escala, com sua ênfase na posicionalidade, no enraizamento [embeddedness] e nos processos de reescalonamento [rescaling] deve ser o foco central das pesquisas sobre políticas de escala.

A terceira intervenção é a recente desconstrução da escala geográfica por Sallie Marston, John Paul Jones e Kevin Woodward (MARSTON et al., 2005), que questionaram a existência de alguma utilidade na análise de política espacial em termos de escalas. Eles sustentam que a teoria dominante de escala é um modelo vertical e hierárquico que perpetua quatro falhas conceituais (2005, p. 419-22): (1) cria uma distinção injustificada entre escala como tamanho e escala como nível; (2) estabelece um conjunto de binômios insustentáveis como macro-micro, ou local-global; (3) constrói uma "epistemologia de rede" espaço-científica que classifica os eventos, objetos e processos em limitados aparatos de escala; e (4) fundamenta-se no perspectivismo metodológico, o que Haraway (1991) designa por "truque divino" (God-trick). A queixa principal dos autores, porém, é que as bases conceituais da escala hierárquica são politicamente retrógradas porque reproduzem inutilmente as desigualdades socioespaciais e neutralizam as possibilidades de resistência. A escala hierárquica, afirmam, "traz consigo pressupostos que podem delimitar pontos de ingresso na política" (2005, p. 427). Além disso, as tentativas de "complexificar" a escala mediante a introdução de elementos adicionais, tais como as formulações de rede (AMIN, 2002; LEITNER, 2004; TAYLOR, 2004), não ultrapassam os problemas encerrados em uma ontologia escalar hierárquica.

No lugar da escala, os autores propõem uma "ontologia plana" que se baseia em teorias ator-rede (actor-network theory, ANT) e concentra-se em sítios [sites] de interação social específicos (cf. SCHATZKI, 2002). Em contraste com uma hierarquia vertical de escalas, essa abordagem advoga locais - ambientes contextuais compostos de práticas e ordens, humanas ou não - como as entidades espaciais básicas a partir das quais a teorização socioespacial deve ser construída. Sempre emergentes, os sítios [sites] são continuamente transformados pelo estabelecimento de conexões em rede com espaços mais amplos. Porém, essa ontologia plana, argumentam eles, descarta toda a bagagem conceitual de escala, criando assim espaço suficiente para desafiar a nossa presente hierarquia espacial.

Distinção da escala como categoria de análise e como categoria da prática

Partilho as preocupações expressas por Jonas, Brenner e Marston et al. e vejo mérito em seus diagnósticos da confusão conceitual e dos problemas muitas vezes existentes na literatura que envolve escala e política de escala. Contudo, cada crítica captura, na minha opinião, apenas parte de um problema subjacente mais fundamental: as descrições de escala geográfica - em especial no âmbito da tradição políticoeconômica - falham por mesclar de forma irrefletida a escala como uma categoria cotidiana da prática com o seu tratamento como uma categoria substancial de análise. Além disso, a anulação dos aspectos práticos da escala em uma crítica teórica do termo por Marston et al. leva-os a oferecerem uma prescrição incrivelmente equivocada para desvendar os problemas complicados que o conceito coloca para a teoria geográfica. Voltarei a este último ponto mais adiante neste texto.

Antes de continuar com o ponto central da primeira reivindicação, porém, quero ressaltar que ela se 
baseia na crítica de Rogers Brubaker ao tratamento de categorias de "identidade" - especialmente de nações e grupos étnicos - nas ciências sociais. Além disso, vou me referir várias vezes ao trabalho de Brubaker ao formular o meu argumento. Há três razões para isso. Em primeiro lugar, penso que existem vários paralelos instrutivos nos avanços simultâneos da teorização de escala e de identidade das duas últimas décadas especialmente no que diz respeito a questões relativas ao estatuto ontológico de escalas e das identidades em resposta a críticas construtivistas de categorias recebidas. Em segundo lugar, categorias de escala e de identidade estão muitas vezes intimamente atreladas, tanto na prática quanto na análise (KAPLAN, 1999). Por fim, acredito que situar as teorias de escala geográfica dentro do contexto do pensamento construtivista social mais amplo nas ciências sociais pode ajudar a trazer clareza a alguns dos improdutivos debates recentes sobre escala na geografia humana (PURCELL, 2003).

Para começar, é útil delinear o que se entende por categorias de prática e análise. Com base em uma distinção feita por Bourdieu, Brubaker e Cooper (2000, p. 4) definem as primeiras como "categorias da experiência cotidiana, desenvolvidas e implantadas pelos atores sociais comuns" e as últimas como "categorias distantes da experiência usadas pelos cientistas sociais". Evidentemente, muitos termos em ciências sociais "escala", "nação", "identidade", "local" e "classe", para citar apenas alguns - operam em ambas as categorias, prática e análise. Ademais, muitas vezes há "ligação recíproca próxima e influência mútua entre seus usos práticos e analíticos" (BRUBAKER; COOPER, 2000, p. 4). Por exemplo, a categoria "nação" é usada diariamente por atores "leigos" por vários motivos: compreender o seu mundo, promover projetos políticos (tanto opressivos quanto emancipatórios), gerar coesão social etc. Ela também é usada por cientistas sociais para analisar o nacionalismo.

Essa mistura de termos ao mesmo tempo como categorias de análise e prática não é problemática em si. Mas muitos termos que usamos - como nação - constituem "sociologias populares" (HIRSCHFELD, 1996) estabelecidas pelo senso comum, por meio das quais damos sentido ao mundo. Como tal, elas tendem a ser reificadas no pensamento social como entidades essenciais e naturais, e esses entendimentos reificados são muitas vezes adotados acriticamente por cientistas sociais como categorias de análise. Assim, ao aceitar a noção de que as nações existem realmente, nós "consideramos uma categoria inerente à prática do nacionalismo - as concepções realistas, e reificantes, de nações enquanto comunidades reais - e tornamos essa categoria central para a teoria do nacionalismo" (BRUBAKER; COOPER, 2000, p. 5, grifo do autor). Essa manobra é problemática, porque as nações "não são coisas no mundo, mas perspectivas sobre o mundo - realidades não ontológicas, mas epistemológicas" (BRUBAKER et al, 2004, p. 45). Por conseguinte, como cientistas sociais devemos procurar explicar os processos pelos quais o sentimento nacional de grupo se cristaliza - por quem e através de quais práticas a ficção social de grupos étnicos e nacionais que sustenta o poder de apelos nacionalistas se consolida - e não os reproduzir em nossos relatos.

As escalas geográficas, como a "local", "nacional" e "global", também estão profundamente enraizadas como "ficções intuitivas" (SMITH, 2003, p. 35) que informam os nossos entendimentos populares acerca da organização espacial do mundo. Além disso, tal como a ficção política das nações, a noção de que as escalas são níveis, plataformas ou arenas socioespaciais realmente existentes é muitas vezes naturalizada na investigação de cientistas sociais, como sugerem as definições de Smith e Swyngedouw citadas acima. Para destacar um outro exemplo proeminente, lembremo-nos da afirmação de Peter Taylor de que "as três escalas - global, nacional e urbana - são tão naturais quanto a divisão, feita pelas ciências sociais, das atividades em econômicas, sociais e políticas. Esta organização espacial simplesmente nos é dada" (1982, p. 21).

Nessa tentativa inicial - e ainda influente - de teorizar a escala dentro da tradição da economia política, Taylor reformula a teoria de sistema-mundo de Immanuel Wallerstein para criar uma tipologia da "economia política de escala" que explique a existência aparentemente natural desse sistema tripartite de escalas. Ele identifica três campos espaciais: (1) a escala da economia mundial, a escala da "realidade", ou a escala que "realmente importa", porque é o nível em que o capital global é organizado e acumulado; (2) a escala urbana da "experiência", na qual os indivíduos vivem suas vidas diárias e encontram as repercussões do mercado, e (3) a escala do Estadonação, da 'ideologia', porque proporciona um quadro que "separa" nossa experiência diária na vida urbana da realidade de acumulação em escala global" (1982, p. 24-31). Na visão de Taylor, esta trindade de escalas é um aspecto integral do sistema-mundo, porque sua existência é necessária para a acumulação de capital. Consequentemente, embora ele rejeite a alegação de que se trata de princípios de organização socioespacial antigos e "naturais", ele os trata como dados ontológicos em uma economia capitalista mundial (HOWITT, 2002). Assim, de modo semelhante ao exemplo de Brubaker das 
teorias do nacionalismo discutidas anteriormente, Taylor vê essas escalas não apenas como parte da prática do capitalismo global, mas como categorias espaciais analíticas essenciais - e funcionalmente causais (AGNEW, 1993).

\section{Socialmente construída, mas ainda reificada}

Os desafios pós-estruturalistas do último par de décadas tornaram insustentável tomar como certas muitas das nossas categorias analíticas proeminentes, como as de nação ou escala. Em resposta a essa crítica, os cientistas sociais desenvolveram análises "construtivistas" que enfatizam a fluidez, a multiplicidade e a natureza socialmente construída das categorias sociais. Por exemplo, as nações e outros grupos étnicos não são mais descritos como entidades primordiais enraizadas em laços biológicos ou em antigas afinidades. Em vez disso, são definidos como constructos modernos gerados por processos de modernização e do capitalismo, ou pela manipulação de empresários políticos por meio da "invenção da tradição" (HOBSBAWM; RANGER, 1983). Além disso, essas identidades socialmente construídas são geralmente vistas como relativamente fluidas, maleáveis e fragmentadas de múltiplas maneiras.

Mas as tentativas construtivistas de "desessencializar" categorias sociais fundamentais, muitas vezes, permanecem incompletas, mantendo uma "amálgama desconfortável de linguagem construtivista e argumentação essencialista" (BRUBAKER; COOPER, 2000 , p. 6). Por exemplo, as questões ainda comumente debatidas, como "o que é uma nação?" ou "o que é escala?" (cf. COX, 1996, p. 668), pressupõem "a existência da entidade que está sendo definida" (BRUBAKER, 1996, p. 14). Assim, continua a haver um pressuposto implícito em muitas pesquisas construtivistas de que, embora nossas categorias como nação ou escala nacional possam ser contingentes e fluidas, uma vez construídas socialmente elas são tratadas como tão reais e fixas quanto fatos ontológicos.

Os geógrafos humanos têm respondido ao desafio social construtivista na academia, salientando que as escalas também não são dados, mas constructos sociais contingentes, continuamente construídas e reconstruídas. Apesar disso, da mesma forma que categorias de identidade como nação ou grupo étnico, "as categorias de escala permanecem muito mais fixas do que o debate mais recente sugeriu" (HOWITT, 2003, p. 139), e apesar da ênfase na construção e na fluidez, o estatuto das escalas enquanto entidades realmente existentes, que constituem o contexto espacial dentro dos quais e entre os quais a ação social tem lugar, ainda é tacitamente (para dizer o mínimo) presumido na maioria das definições de política de escala.

Para demonstrar essa proposição, quero comentar brevemente a posição teórica sobre a construção de escalas e políticas de escala que Neil Smith desenvolveu brilhantemente em um artigo influente sobre moradores de rua em Nova York e escala geográfica (1993). Eu acredito que o foco no trabalho de Smith é instrutivo em dois aspectos. 0 primeiro é que ele tem sido um dos colaboradores mais originais e influentes para a teorização das políticas de escala nas duas últimas décadas, enriquecendo o vocabulário dos geógrafos com uma série de conceitos provocativos (no sentido mais positivo da palavra), tais como "salto de escala" (scale jumping), "dobra de escala" (scale bending), "política de escala" (politics of scale) e "ajuste escalar" (scalar fix) (SMITH, 1984; 1992; 1993; 1996; 2004). Em segundo lugar, o trabalho de Smith fornece uma excelente demonstração das tendências reificantes remanescentes dentro de entendimentos de escala influenciados pelo construtivismo social.

Eu começo por assinalar que a abordagem de Smith para a construção social de escala é fortemente influenciada por pressupostos político-econômicos. Processos econômicos gerados pelo capitalismo estão ligados à produção de escalas e à política de escalas. No entanto, ele expande sua teorização para incorporar também influências sociais e culturais. Sistemas de diferenciação de gênero, em particular, desempenham um papel importante. Consequentemente, as escalas são "hierarquicamente produzidas como parte das paisagens sociais e culturais, econômicas e políticas do capitalismo contemporâneo e do patriarcado" (SMITH, 1993, p. 101). Smith também identifica várias escalas importantes para além do modelo tripartite de Taylor - corpo, casa, comunidade e região - que são socialmente produzidas. Ele observa, porém, que elas não devem ser confundidas com uma proposta de "sistema ontológico de escalas", uma vez que refletem um julgamento empírico, não filosófico. Em outras palavras, são construções sociais contingentes, não fatos ontológicos.

Esta última afirmação encerra uma dicotomia problemática, no entanto, que repousa sobre um pressuposto implícito de que tratar das escalas (ou quaisquer outras entidades sociais e materiais) como dadas ou fixas pressupõe um compromisso ontológico, enquanto vê-las como contingentes e constructos liberta o cientista social dessa obrigação teórica. $\mathrm{Na}$ minha opinião, essa é uma compreensão equivocada da noção de reivindicações ontológicas. Como Elden (2005, p. 16, grifo do autor) observou, "a ontologia 
não está preocupada com 'o que é', mas com a forma como 'o que é, é"'. Em outras palavras, e tomando de empréstimo a expressão útil de Searle (1995), "como tudo se encaixa". Para Smith, assim como para a maioria dos outros geógrafos na tradição político-econômica, as "unidades" espaciais centrais através das quais o mundo "se encaixa" são as escalas. Por isso, elas são um componente integral da sua (assim como para um amplo grupo de geógrafos humanos) ontologia socioespacial.

Para dar um exemplo análogo: muitos teóricos da identidade afirmam que os povos étnicos e nações são constructos, contingentes e fluidos - não fixos ou dados - mas ainda imaginam um mundo habitado por esses grupos. Por isso, eles possuem uma estrutura ontológica na qual grupos étnicos e nações reificados ocupam um lugar central na vida social (BRUBAKER, 2002). Da mesma forma, a reivindicação de Smith $(2000$, p. 726$)$, de que "as escalas geográficas podem não ser tangíveis ou visíveis, mas são reais" é, apesar de suas objeções em contrário, um compromisso com uma ontologia da política espacial que repousa sobre escalas reificadas.

Este último ponto da reificação é melhor ilustrado ao voltar para a discussão de Smith sobre o Veículo dos Sem-teto (Homeless Vehicle), em Nova York, e a sua importância ao permitir aos moradores sem-teto que resistissem a arranjos socioespaciais opressivos. Smith destaca o papel do Homeless Vehicle em criar oportunidades para o "salto de escala" (scale jumping), o qual ocorre quando as reivindicações políticas e o poder estabelecido em uma escala geográfica se estendem para outra. Ao permitir que os sem-teto expandissem sua mobilidade espacial e, assim, tivessem acesso a mais lugares - como diferentes locais para coletar lixo e pedir esmolas, ou centros de reciclagem de garrafa e latinhas - o veículo facilitou "não apenas a produção do espaço no abstrato, mas a produção e reprodução concretas da escala geográfica como uma estratégia política de resistência" (1993, p. 90, grifo do autor). Como resultado, a mobilidade que o Homeless Vehicle dispõe "permite que pessoas despejadas ou desapropriadas dissolvam as fronteiras espaciais a que são impostas de cima e que as contêm em vez de facilitar a sua produção e reprodução da vida cotidiana" (1993, p. 90). Em outras palavras, o Homeless Vehicle permite às pessoas saltarem escalas no sentido "concreto" de romper fisicamente os espaços limitados que as continham um parque, por exemplo -, libertarem-se dos limites de escala impostos e estenderem seu alcance para escalas maiores e mais amplas.

Esta é uma descrição reveladora de escala geográfica que Smith fornece, misturando ao mesmo tempo noções de escala como tamanho e nível (HOWITT,
1998; 2002). Mais problemática é a noção de "salto de escala" (scale jumping), que conceitualmente separa as escalas das práticas sociais, apresentando escalas como "resoluções espaciais já existentes (mesmo que socialmente produzidas) por entre as quais os atores sociais simplesmente mudam de lugar" (HERODES; WRIGHT, 2002, p. 11). Em suma, as escalas no quadro teórico de Smith continuam a ser tratadas como níveis espaciais separados e ordenados hierarquicamente "plataformas" espaciais concretas em torno das quais a vida diária e a ação política são organizadas - e essas escalas muito materiais e reais servem como a "métrica central da diferenciação geográfica" (SMITH, 2000, p. 725). Quando estendida para os níveis já tidos como verdades absolutas, como o urbano, o regional, o global, o nacional e o local, essa conceituação que busca a essência das escalas socialmente construídas produz um quadro analítico de escalas reificadas que se torna uma suposição teórica crítica em muitas definições influentes da política de escala.

Este último ponto é melhor demonstrado quando se retorna ao modelo de estruturação escalar desenvolvido por Brenner, que recorre à mesma tradição políticoeconômica do trabalho de Smith. Na visão de Brenner, a necessidade de resolver a contradição entre fixidez e movimento na circulação do capital exige a criação periódica de arranjos escalares que temporariamente territorializam e, assim, contêm as tendências de aniquilação de espaço pelo capital. Isto ocorre por meio da "estruturação escalar", que envolve a criação de "relações de hierarquização e re-hierarquização entre unidades espaciais diferenciadas verticalmente" (BRENNER, 2001, p. 603). Brenner enfatiza os aspectos historicamente contingentes e processuais de estruturação escalar, insistindo que "a noção de uma política de escala referese à produção, à reconfiguração ou à contestação de determinadas diferenciações, ordenamentos e hierarquias entre as escalas geográficas" (2001, p. 600 , grifo do autor).

Oproblemaéquenestaformulação dapolítica deescala "certas diferenciações, ordenamentos e hierarquias" são o material que está sendo produzido, contestado e reconfigurado. As escalas geográficas existem para além do processo de estruturação escalar e seus atributos essenciais permanecem intocadas por este último. $\mathrm{Na}$ verdade, elas são continuamente embaralhadas, como cartas de baralho, com o reordenamento de suas relações variáveis (SWYNGEDOUW, 2004, p. 133, afirma que "as contínuas redefinição e reorganização de escalas espaciais são parte integrante de estratégias sociais"). Além disso, a explicação esquemática de Brenner para a acumulação capitalista amalgama irregularidade e 
variabilidade em um punhado de escalas, como global, nacional e local, com a atribuição de causalidade à escala global para explicar a atual rodada de reestruturação (MANSFIELD, 2001). Portanto, embora Brenner considere as escalas como produzidas e contingentes, em última análise ele as trata como entidades "reais" que são tão analiticamente e casualmente centrais em seu edifício teórico quanto o eram para Taylor.

Escala como categoria analítica: problemática e desnecessária

Neste ponto, o leitor pode estar tentado a perguntar: e então? Esta é apenas mais uma tentativa pósestruturalista de desconstruir categorias analíticas úteis, deixando apenas um rastro de destroços inúteis para trás? Se não usarmos escalas, então o que usaremos? Dito de outra forma, duas objeções básicas ainda precisam ser comentadas: (1) qual é o problema de reificar escalas e, em seguida, utilizá-las como categorias de análise, e (2) como devemos conceituar a política de escala?

Inicio a resposta à primeira questão pela observação de que preocupações semelhantes foram expressas antes quanto ao abandono de categorias de identidade, tais como a de grupos étnicos ou a de nação (TILLY, 2002; CALHOUN, 2003). No entanto, uma breve discussão sobre as tentativas de explicar o surto de violência na Bósnia no início dos anos 1990 pelo uso de identidades étnicas reificadas como categorias de análise é suficiente para demonstrar os graves problemas analíticos que tal compromisso implica. Em primeiro lugar, a reificação de grupos étnicos sérvios, croatas e bósnios pré-configura, como pressupostos, entidades e formas de vida social essenciais. No caso do conflito na Bósnia, isso complicou a análise por ter tornado difícil conceituar a interação social conflituosa entre membros desses supostos grupos como nada além de "étnica". No entanto, tem sido amplamente demonstrado que muitos casos de violência aparentemente étnica na Bósnia foram, após uma análise mais aprofundada, vinganças locais ou combates entre as redes criminosas (BAX, 1997; 2000; MUELLER, 2000; ANDREAS, 2004). Assim, identidades de grupo reificadas na pesquisa como "conflitos étnicos" criam um quadro analítico como "dado" (a base étnica do conflito), enquanto na verdade se trata de uma questão empírica a ser investigada.

Em segundo lugar, por esse enquadramento, grupos étnicos reificados são normalmente tratados como atores coerentes e usados para explicar os casos de conflito violento (KALYVAS, 2006). Novamente, isso pressupõe um grau de coesão étnica que não pode ser tomado como um fato. Mais importante ainda, isso desvia a atenção dos atores políticos específicos e das organizações envolvidas na produção do conflito e no seu enquadramento como étnico. No entanto, como já comentado acima, são precisamente as práticas reificantes étnicas desses atores e organizações que devem ser o ponto focal de nossa pesquisa, não a ficção política de grupos étnicos que eles invocam e tentam cristalizar como aparentemente "reais", a fim de promover projetos políticos (BRUBAKER, 2002).

No caso de adotar escalas reificadas como categorias de análise, um conjunto similar de problemas surge. Primeiro, a aceitação de uma ontologia da escala gera uma série de suposições apriorísticas questionáveis sobre o que "sabemos" acerca da política espacial. Tal como acontece com os grupos étnicos, assumir que as escalas são reais pressupõe a existência de "processos em escala" [scaled processes] ou de políticas de escala entre níveis ou unidades de escala, o que torna "difícil não pensar em termos de relações sociais e arranjos institucionais que de alguma forma se encaixam em seus contornos" (MARSTON et al., 2005, p. 422). Por muitas vezes isso leva a uma análise procusteana ${ }^{1}$ que tenta encaixar políticas espaciais complexas dentro dos estreitos limites de um punhado de escalas conceitualmente estabelecidas, como local, nacional ou global. Ademais, promove uma aceitação acrítica de "figuras de representação" de escala utilizadas pelos vários atores políticos (JONES, 1998). Ao partir do pressuposto de que "ficções intuitivas" como as escalas correspondem a entidades ou processos materiais reais "lá fora", corre-se o risco de usar representações de escala de indivíduos e instituições, que correspondem a presumidos quadros analíticos, como prova confirmativa, em vez de projetos socioespaciais e manobras políticas a serem interrogados.

Além disso, utilizar escalas como categorias analíticas dirige a atenção para longe dos vários atores e práticas sociais envolvidos na política de escala. A tradição político-econômica tem sido objeto de repetidas críticas por seu foco limitado sobre as forças do capital e do Estado na política de escala (cf. MARSTON, 2000) e temse implorado aos geógrafos que considerem o papel de uma gama mais ampla de atores, como os ativistas da AIDS (BROWN, 1995), os trabalhadores (HERODES, 1997), os partidos políticos (AGNEW, 1997), as ONGs ambientais (KURTZ, 2003; McCARTHY, 2005) e as organizações de grupos urbanos (MARTIN 2003; McCANN, 2003), para listar apenas alguns exemplos. Essas intervenções foram

${ }^{1}$ Alusão a Procusto, personagem da mitologia grega que amputava ou esticava os corpos de seus visitantes a fim de encaixá-los na cama de hóspedes. (notas dos revisores) 
louváveis e necessárias na medida em que ampliamos nossa apreciação sobre a diversidade do elenco de participantes envolvidos na política de escala e o extenso repertório de práticas escalares que empregam. No entanto, elas não conseguiram desalojar a escala como construção analítica de sua posição privilegiada na pesquisa sobre a política de escala, limitando assim a eficácia das suas críticas. Enquanto a escala como uma categoria importante de análise é o ponto focal da pesquisa geográfica, as práticas escalares de atores sociais tendem a permanecer à margem da atenção da disciplina.

Por último, o tratamento de escalas como níveis, plataformas ou arenas estabelecidas da política diminui e distorce uma variedade de processos socioespaciais ao eliminar as diferenças e a granularidade espaciais, além de simplificar excessivamente a posicionalidade espacial complexa e múltipla dos atores e eventos sociais. Esse problema foi demonstrado vigorosamente na crítica de John Agnew (1987) aos pressupostos espaciais homogeneizantes contidos na literatura sobre a nacionalização nas ciências sociais. Mas os geógrafos também tendem a presumir um grau de coesão e similaridade entre os supostos níveis de escala e, posteriormente, atribuem um leque de rótulos duvidosos ou figuras metafóricos para escalas - "local" = estático e autêntico; "global" = dinâmico e produzido etc. - além de lugares, atores e processos que a elas se vinculam (LEY, 2004;. MARSTON et al, 2005). Com efeito, esse problema é inerente a conceituações reificadas das escalas enquanto níveis, plataformas ou arenas das lutas sociais (SWYNGEDOUW, 1992b, p. 60): uma gramática espacial que reduz escalas a recipientes [container] - unidades de área delimitadas que abrangem e definem as pessoas $\mathrm{e}$ os processos supostamente localizados em seu interior.

A crítica aprofundada de Marston et al. da escala concentra-se principalmente em noções de hierarquia vertical, mas considero esta lógica embutida de "receptáculo espacial" tão fundamental para a teorização da escala quanto a diferença hierárquica. Na verdade, esses dois atributos estão tipicamente conectados inseparavelmente nas definições de escala de geógrafos. Como Brenner observa (2000, p. 374), seguindo Lefebvre, "as escalas operam simultaneamente como recipientes [container] territoriais e hierarquias geográficas das relações de poder cotidianas". Esta dupla caracterização de escalas como arenas socioespaciais, tanto limitadas horizontalmente quanto ordenadas verticalmente ou hierarquicamente (ou seja, por suas relações), introduz grandes complexidades teóricas e poderes para o conceito (COLLINGE, 2005). Talvez até demais, como alguns críticos (HOWITT, 2002;. MARSTON et al., 2005) reclamam, observando que a escala contém uma combinação problemática de raciocínio espacial horizontal e vertical.

Isto pode ser correto, mas esta crítica erra, em última análise, o alvo. As premissas geográficas, como espaços e relações ordenados de forma hierárquica e delimitados horizontalmente, refletem apenas entendimentos bastante comuns, práticos, do espaço e das relações espaciais (SACK, 1980). Em contraste com discursos teóricos da moda sobre a fluidez, imensidão e extensão, quando as pessoas se envolvem na política prática "imaginam e identificam um espaço circunscrito, delimitado, caracterizado por uma compreensão compartilhada das oportunidades ou problemas que motivam a verdadeira natureza da ação política" (JONES; MacLEOD, 2004, p. 437). O problema é que essas noções cotidianas de escala foram inadvertidamente transportadas para nossas análises de política espacial, transformando assim integralmente uma ideia geográfica - e toda a bagagem conceitual concomitante - usada na prática da política espacial e elevando-a ao status de um elemento fundamental da teoria. Para voltar à crítica de Brubaker (2002, p. 165) do "grupismo" étnico do senso comum encontrado nos quadros analíticos de cientistas sociais e aplicá-la à escala: a tendência a separar o mundo social em "recipientes" [containers] espaciais hierarquicamente ordenados é o que queremos explicar - e não explicar as coisas por meio destes recipientes.

\section{Como lidar, então, com a escala e a política de escala?}

Claramente, nossas concepções atuais de escala estão sobrecarregadas por uma série de pressupostos problemáticos e desnecessários. Não está claro, além disso, por que os geógrafos continuam a manter um compromisso com a escala como uma categoria de análise, perpetuando uma ontologia espacial da escala. Nesse sentido, estou suficientemente de acordo com a intervenção recente de Marston et al. No entanto, a sua proposta para acabar não apenas com uma ontologia hierárquica de escala, mas "eliminar a escala como um conceito em geografia humana" (2005, p. 416) - assim como, presume-se, qualquer referência à política de escala - é como jogar fora o bebê junto com a água do banho. Ironicamente, dada a sua dispensa de várias armadilhas binárias perpetuadas por modelos de escala hierárquicos, por meio dessa manobra teórica os autores estão inconscientemente reproduzindo uma dualidade materialista/idealista que: (1) inutilmente centra o debate no estatuto ontológico e teórico de escalas em geografia humana, em detrimento da atenção à sua existência e 
ao seu uso enquanto categorias práticas, e (2) repousa sobre o pressuposto falho de que negar a realidade ontológica de escalas implica no fato de as escalas serem simplesmente heurísticas inconsequentes nas mentes dos geógrafos que "não têm utilidade", ou não têm efeito em si mesmas.

Essas alegações podem parecer estranhas, como quando Marston et al. (2005, p. 420) admitem que a escala existe como um "quadro de ordenação epistemológica". Mas a sua afirmação de que os geógrafos têm apenas três escolhas possíveis para repensar as escalas defender a abordagem hierárquica com pequenas revisões; desenvolver modelos híbridos verticais/ hierárquicos de escala; ou abandonar a escala em favor de uma "ontologia plana" - denuncia uma conceituação de escala que é fixa em questões de natureza teórica e deixa de lado práticas cotidianas de escala e seus efeitos materiais. Seu argumento, então, demonstra outro problema que surge quando se privilegia a escala como uma categoria de análise em detrimento dos compromissos práticos com categorias de escala e seus usos pelos diversos atores sociais e políticos. Em suma, embora eu concorde com Marston et al. que a escala éuma realidade epistemológica, e não ontológica, a princípio a aparente incongruência de ficções ontológicas - como as escalas locais, urbanas, nacionais ou globais - terem uma influência tão poderosa na política socioespacial clama por mais atenção à forma como a escala funciona como uma categoria da prática.

Além disso, não é necessário manter um compromisso com a existência de escalas, a fim de analisar a política de escala. Assim como podemos pesquisar práticas nacionalistas sem assumir que as nações são entidades reais, é possível desenvolver teorias sobre a política de escala sem escalas. Como se faz isso evitando a armadilha da reificação? Em sua crítica da tendência dos estudiosos a adotarem nações como uma categoria de análise, Brubaker (1996) oferece a seguinte solução:

Não devemos perguntar 'o que é uma nação?',
mas: como a condição de nação [nationhood] é
institucionalizada como uma forma política e cultural
dentro e entre estados? Como a nação passa a ser
uma categoria prática, um esquema classificatório,
um quadro cognitivo? [...] O que faz os esforços para
o despertar da nação e por invocar uma nação dos
empresários políticos terem mais ou menos chance de
sucesso? (p. 16)

A importância de se fazer uma distinção entre nação e o sentimento de nação é que isso nos obriga a mudar nosso foco da nação como uma categoria importante de análise para o de sentimento de nação - a cristalização de sentimentos e práticas sobre ser uma nação - como um evento contingente, colocando assim a ênfase sobre o processo de nacionalização. Esta distinção sensibilizanos para o grau variável em que o sentimento nacional é vivido, abre à investigação tentativas fracassadas de nacionalização e dirige a nossa atenção para as práticas e os processos que geram casos marcantes de sentimento de nação. Ela também reorienta a pesquisa para as consequências dos processos de nacionalização - as maneiras em que a sedimentação do discurso de nação e as práticas mudam as relações sociais.

Esta manobra analítica também pode ser proveitosamente adotada para abrir novos caminhos para teorizar a política de escala. Tratar escalas como conjuntos de uma forma ou de outra poderosos e institucionalizados de práticas e discursos em vez de coisas concretas (PAASI, 2004, p. 537) impelenos a considerar os processos através dos quais configurações de escala específicas se solidificam na consciência e na prática, bem como os efeitos que esses desenvolvimentos têm sobre as relações sociais, políticas e culturais. Para concluir, gostaria de esboçar uma lista preliminar - e, sem dúvida, incompleta - de questões de pesquisa que vêm à tona quando tratamos a escala como uma categoria prática. Muitas delas estão implícitas na seção acima que discutiu os problemas inerentes a uma ontologia de escala. Seis grandes áreas, em particular, se destacam.

\section{Escala como epistemologia}

O reconhecimento de que as escalas não são categorias substanciais de análise, mas categorias de prática, dirige nossa atenção para as maneiras pelas quais narrativas, classificações e esquemas cognitivos de base escalar restringem ou permitem certas formas de ver, pensar e agir. Isso abre para a investigação uma série de questões sobre como a escala funciona como epistemologia, moldando o que "sabemos" sobre o mundo. Afirmar que as escalas são realidades epistemológicas - não ontológicas - não diminui sua importância. Pelo contrário, alerta-nos para as formas reais e importantes pelas quais a categorização de escala estrutura não apenas as percepções pessoais, mas também as relações sociais, uma vez que "não há nada mais básico, para nosso pensamento, nossa percepção, nossa ação e nosso discurso, do que a categorização" (LAKOFF, 1987, p. 5). Por conseguinte, observam-se resultados muito relevantes quando formulações de escala específicas são divulgadas e utilizadas com sucesso por atores políticos e instituições poderosos para promover projetos políticos específicos.

Um exemplo bem conhecido é o papel que os vários 
usos da categoria de escala "nacional" desempenha na construção de cidadãos, envolvendo-os nos "recipientes" do Estado territorial, um aspecto-chave da governabilidade (FOUCAULT, 1991). Seguindo Foucault, Ferguson e Gupta (2002) afirmam que produção de verticalidade e abrangência de escala são a raison d'être dos Estados. A percepção de que os Estados funcionam como um recipiente [container] socioespacial que constrói uma arena "interna" de política estabelecida abaixo do âmbito "externo" dos assuntos internacionais foi explicada repetidas vezes em geografia política e relações internacionais nos últimos anos (WALKER, 1993; AGNEW, 1994; TAYLOR, 1994; BRENNER, 1999). Mas as epistemologias da escala nacional não se limitam a apoiar Estados territorialmente delimitados; elas também contribuem para a tendência generalizada - entre acadêmicos e leigos - de pensar em "sociedades nacionais" como unidades semelhantes a recipientes homogêneos e separados (MANN, 1986; TAYLOR, 1996; HAKLI, 2001), o que por sua vez gera temas de estudo estáticos e redutores, tais como a sociedade "alemã" ou "tailandesa" (TILLY, 1984, p. 20-26). A escala nacional, então, é um ponto particularmente valorizado em que o "agrupamento analítico" da teoria da identidade cruza com o "confinamentismo" [containerism] espacial da escala.

É claro que pensar e organizar espaços, pessoas, eventos e relações sociais em espaços delimitados se estende para além das especificidades do poder do Estado ou de manobras capitalistas. $\mathrm{Na}$ verdade, como já mencionado acima, essa forma de raciocínio espacial é tão central para as ideias e práticas de uma política espacial "de escala" quanto a noção de relações verticais e hierárquicas entre as escalas. Para tomar emprestada uma frase feliz de Hayden White (1987), a delimitação horizontal e o ordenamento vertical ou hierárquico da vida socioespacial simultâneas na escala são típicos "conteúdos da forma". Com isso quero dizer que, na prática, conceituações e projetos políticos escalares envolvem uma identificação e classificação simultâneas dos níveis horizontalmente delimitados de espaço e da vida social e o ordenamento relacional destas delimitações espaciais. Por essa razão, convites à separação de funções singulares e plurais da política de escala (BRENNER, 2001) ou à separação da "mistura de discurso de escala com o discurso de fronteira" (MARSTON et al, 2005, p. 428) são altamente improdutivos, pois dividiriam aspectos do conceito que - independentemente de suas propriedades teóricas problemáticas ou contraditórias - formam um todo epistemológico no discurso cotidiano sobre a escala. Em vez disso, devemos perguntar: como pessoas, lugares, eventos, ações e relações sociais são classificados nesses termos (JONES, 1998)? O que torna mais ou menos provável que determinadas categorizações e abordagens escalares passem a ser postas em prática?

\section{Categorização de escalas e práticas de classificação}

Essas perguntas concentram a atenção diretamente sobre processos de categorização de escalas: a construção, reprodução e dissolução das classificações de escala específicas e as diversas práticas sociais nelas envolvidas. Nesse sentido, os cientistas sociais produziram uma rica literatura sobre as práticas de classificação socioespaciais. Novamente, os Estados foram apontados como atores centrais. Os Estados promulgam sistemas nacionais de moedas e selos postais (HELLEINER, 2002; RAENTO; BRUNN, 2005); encomendam mapas do estado (WINICHAKUL, 1994); nomeiam monumentos e ruas (JOHNSON, 1995; YEOH, 1996), realizam censos (PATRIRCA, 1996; HIRSCH, 2005); emitem passaportes e constroem regimes de fronteira (TORPEY, 2000; FERME, 2004), para citar alguns exemplos. No processo, eles naturalizam o Estado-nação como uma escala central de identidade e poder político. Ademais, os Estados se esforçam para estabelecer uma ordem escalar hierárquica dentro de suas fronteiras por meio da introdução de jurisdições espaciais e legais, tais como "município", "província" e "região"3. Talvez o relato mais detalhado da difusão de categorias de escala pelo Estado como um projeto de institucionalizar uma sociedade nacional e um governo delimitados e ordenados por suas relações é a análise de Paasi (1996) dos esforços da Finlândia para habituar moradores de Carélia à consciência de um eixo vertical encaixado de escalas (casa-região-pátria-outros países) ancorado na delimitação do Estado-nação finlandês e construído em oposição aos povos e territórios de fora - em particular à União Soviética e à Rússia.

Enquanto as práticas de classificação estatais são importantes, os atores "leigos" também desempenham um papel significativo na categorização socioespacial, e frequentemente subvertem ou alteram classificações oficiais para seus próprios propósitos. Eles utilizam narrativas para "interiorizar" e "exteriorizar" as relações socioespaciais e criam para si tramas de novas configurações de escala (PAASI; NEWMAN, 1998; KAISER; NIKIFOROVA, 2006). A criação de narrativas é um aspecto fundamental de classificação social e espacial - tanto oficial quanto cotidiana, pois "todos nós nos tornamos o que somos (embora efêmeros, múltiplos e em constante mudança) por estarmos localizados ou por localizarmos a nós mesmos (normalmente inconscientemente) em 
narrativas sociais" (SOMERS, 1994, p. 606, grifo do autor). Narrativas, assim, não são apenas formas de representação. Elas "situam" pessoas e ocorrências no espaço e no tempo, dando assim sentido espacial e temporal a eventos e relações (DE CERTEAU, 1984). Ao fazê-lo, agem como "mapas de ação" (RICOUER, 1991), fornecendo uma perspectiva para o agir consciente.

\section{Raciocínio e cognição espacial}

Seguindo um padrão geral na teoria social e na ciência nas últimas décadas, as análises destacadas na seção anterior colocam uma forte ênfase no papel das práticas sociais em produzir categorias sociais e espaciais salientes, assumindo que essas práticas de classificação moldam a consciência individual. Tais pesquisas raramente examinam as premissas cognitivas implícitas sobre as quais repousam. Na geografia humana, essa tendência pode, em parte, ser atribuída a uma relutância em nos envolver com qualquer coisa que se assemelhe ao "behaviorismo" na esteira de veementes críticas humanistas e marxistas das abordagens positivistas e cognitivas que as antecederam. Considero isso um erro. As análises feitas por geógrafos da dinâmica de categorização socioespacial demandam ser enriquecidas por um compromisso explícito com a pesquisa cognitiva recente que ilumina as maneiras pelas quais as pessoas compreendem as experiências, que por sua vez moldam a maneira como se envolvem no mundo.

A ciência cognitiva é um campo vasto, cuja revisão está para além do escopo deste artigo. Eu gostaria, porém, de destacar brevemente um dos seus pontos de intersecção mais promissores: o trabalho de Lakoff e Johnson (LAKOFF; JOHNSON, 1980; 1999; JOHNSON, 1987; LAKOFF, 1987) sobre a mente incorporada [embodied mind] e o raciocínio espacial ${ }^{4}$. Os autores afirmam que a ciência cognitiva demonstrou que: (1) a mente é inerentemente incorporada [embodied]; (2) o pensamento é principalmente inconsciente; e (3) conceitos abstratos são em grande parte metafóricos (1999, p. 3). 0 que isso significa é que, como seres corporais, nosso raciocínio não é puramente consciente e literal (como postulado por adeptos do dualismo cartesiano mentecorpo), mas em grande parte inconsciente, metafórico e imaginativo do ponto de vista cognitivo. Os principais conceitos e esquemas de imagem - cor, categorias de nível básico e (especialmente) relações espaciais - são derivados de nossas experiências corporais, sensoriais e cinestésicas. Por sua vez, por meio do mapeamento metafórico entre domínios, esses esquemas básicos, incorporados, compõem os blocos de construção de um raciocínio mais complexo, abstrato. Em outras palavras, nossos pensamentos e conceitos abstratos são sempre moldados (frequentemente sem que estejamos plenamente conscientes disso) por esquemas de imagem básicos que são em grande parte de natureza espacial.

Tomemos como exemplo o esquema do recipiente [container], que surge a partir da nossa experiência personificada de contenção:

\begin{abstract}
A contenção e a limitação são algumas das características mais difundidas da nossa experiência corporal. Estamos intimamente conscientes de nossos corpos como recipientes tridimensionais nos quais colocamos certas coisas (comida, água, ar) e do qual saem outras coisas (restos de comida e água, ar, sangue etc.) [...] experimentamos a contenção física constantemente em nosso entorno (aquelas coisas que nos envolvem) [...] manipulamos objetos, colocandoos em recipientes (copos, caixas, latas, sacos etc.). (JOHNSON, 1987, p. 21)
\end{abstract}

A estrutura conceitual do esquema de recipiente é composta por três elementos: um interior, um exterior e uma fronteira. Como outros esquemas de imagem (vínculo, caminho, cima-baixo, centro-periferia, partetodo, frente-atrás, etc.), o esquema de recipiente é intermodal - pode ser metaforicamente transposto para outros domínios. Quando isso ocorre, a lógica estrutural do esquema (dentro, fora, limite) é preservada no novo domínio, "como quando um treinador de beisebol quebra a tacada do batedor nas partes que a compõem e discute o que se passa 'dentro' de cada parte" (LAKOFF; JOHNSON, 1999, p. 32). Mais significativamente, nós estendemos, de forma generalizada, a lógica metafórica de esquemas de imagem espacial a eventos não físicos, estados e entidades abstratas. Assim, a frase "Diga-me a sua história de novo, mas deixe de fora os detalhes menores" figurativamente estende o esquema do recipiente para o seu evento na história, construindo-o como uma entidade espacialmente delimitada - "o evento na história como o recipiente" (JOHNSON, 1987, p. 34). Esquemas de imagem espacial, em seguida, têm dois papéis: "eles são conceitos que possuem estruturas próprias diretamente compreendidas e são usados metaforicamente para estruturar outros conceitos complexos" (LAKOFF, 1987, p. 283).

Isso não significa que as pessoas em todos os lugares e a todo momento utilizem esquemas espaciais da mesma maneira. Há grande variação cultural na construção conjunta do pensamento espacial (LEVINSON, 1996). No entanto, o trabalho de Lakoff e Johnson fornece informações valiosas sobre a dinâmica da categorização espacial das relações materiais e sociais, bem como sobre a lógica espacial integrada às construções mais complexas, metafóricas. Expandindo este segundo 
ponto, uma implicação significativa de sua pesquisa é que conceitos geográficos abstratos como escala ou rede não são internamente consistentes ou categorias analíticas fechadas. Pelo contrário, eles são melhor vistos como "semelhanças familiares" (WITTGENSTEIN, 1953) do pensamento espacial - conjuntos flexíveis e heterogêneos (embora reconhecidamente similares) de esquemas de imagem espaciais básicos, tais como recipiente, vínculo, centro-periferia, cima-baixo, partetodo etc. Consequentemente, as formas pelas quais esses vários blocos de construção estão unidos moldam a lógica conceitual das metáforas espaciais, e por extensão a forma como nos envolvemos com o mundo (HEROD, 2003, p. 238).

Isso pode ser observado ao retornar para duas metáforas da escala mencionadas acima: escadas e bonecas matrioska. A metáfora da escada é uma combinação de três esquemas espaciais básicos: recipiente, vínculo e cima-baixo. As escalas são tratadas como níveis não sobrepostos, não interativos e distintos (esquema recipiente), e estão amarradas (esquema vínculo) como uma progressão de "degraus" orientados verticalmente (de cima para baixo) que vão do corpo para o global. A hierarquia é um frequente, embora desnecessário, elemento da metáfora da escada, cujo poder normalmente - mas, repetimos, não necessariamente - aumenta à medida que se sobem ou se saltam escalas (uma instância do esquema "quanto maior, melhor"). A metáfora das bonecas matrioska, em contrapartida, decorre de uma associação dos esquemas de recipiente, parte-todo e "quanto maior, melhor". Mais uma vez as escalas, sob a forma de bonecas individuais, são conceituadas como arenas distintas de espaço (que a contém). No entanto, escalas menores são vistas como progressivamente "encaixadas" dentro das maiores ("quanto maior, melhor") de modo que a maior das escalas, a global, abrange todas os menores (parte-todo). Assim, a metáfora da boneca matrioska difere conceitualmente da escada de três maneiras importantes: (1) as escalas podem se sobrepor ou interagir (isto é, o global "contém" o nacional); (2) essa interação é unidirecional e hierárquica, uma vez que apenas escalas maiores podem abranger ou influenciar as menores (ou seja, o nacional não pode conter o global); (3) a hierarquia é baseada mais sobre a extensão do que sobre a verticalidade.

Essas diferenças ilustram que as metáforas espaciais escolhidas podem afetar significativamente os cursos de ação das pessoas, as estratégias que atores políticos empregam e as relações sociais de poder (CRESSWELL, 1997). Mas o ponto mais importante é que os esquemas espaciais básicos não moldam apenas a lógica de metáforas de escala explícitas, tais como a das escadas ou a das bonecas matrioska; são um aspecto integral de toda a epistemologia e categorização espacial. Compreender o modo como esses blocos de construção que delimitam e ordenam o espaço estão conectados por meio de práticas classificatórias e narrativas, os efeitos que diferentes configurações têm e as contestações sociais sobre o discurso espacial são aspectos urgentes - e subestimados - da pesquisa sobre política de escala.

\section{Projetos e práticas de escala}

O reconhecimento do poder da epistemologia, da categorização e da cognição escalares aponta para um aspecto relacionado com a política de escala que merece maior atenção: o que as pessoas fazem com as categorias de escala, e como elas as utilizam para construir o espaço e relações sociais para fins políticos específicos. Isso implica levar a sério os discursos e práticas dos atores sociais - mas não os incorporar irrefletidamente à nossa análise - de natureza reificante, delimitadores do espaço e definidores de um ordenamento vertical; mudar a nossa orientação em direção a "dimensões escalares das práticas, em vez de práticas que ocorrem em diferentes escalas" (MANSFIELD, 2005, p. 468, grifo do autor).

Recentemente, os geógrafos começaram a lançar luz sobre este aspecto prático da política de escala ao examinar as várias formas como atores utilizam a escala para promover projetos políticos. Eu acredito que vale a pena discutir brevemente alguns exemplos aqui. Um deles é o exame feito por Kelly (1997) das tentativas por parte de empresas multinacionais e Estados de invocar a "escala global" para legitimá-la como uma arena crítica das relações econômicas, políticas e culturais modernas e colocá-la em contraste com os meros contextos "locais". Simultaneamente, uma variedade de instituições, de mecanismos reguladores e de projetos de desenvolvimento são projetados para se alinhar em torno desta plataforma socioespacial aparentemente tangível. Assim, por meio desse processo o poder político e as relações econômicas são transformados e ressituados.

Um segundo caso é a exploração de Agnew (1997) da importância da escala para os partidos políticos italianos na construção de suas visões de "Itália", no início da década de 1990, após o colapso do sistema de partidos. Com uma análise pormenorizada, ele demonstra que cada um dos quatro maiores partidos da Itália ofereceu uma concepção diferente de escala geográfica, e que esses horizontes espaciais concorrentes foram cruciais para a compreensão dos eleitores que estes partidos conseguiram atrair e para a afinidade com seus parceiros de coligação. A política é inerentemente 
geográfica e escalar e os partidos devem organizar a si mesmos e a suas plataformas ideológicas através das maneiras como dividem e ordenam o espaço, conclui Agnew, porque "a política partidária é intrinsecamente uma atividade relacionada ao espaço, mesmo quando ninguém o percebe" (p. 118).

Outro programa de investigação emergente (cf. KURTZ, 2002; 2003; MARTIN, 2003; McCANN, 2003; MANSFIELD; HAAS, 2006) baseia-se no trabalho pioneiro de Goffman (1974) sobre o "análise do enquadramento" [frame analysis] e a literatura sobre movimentos sociais (SNOW et al., 1986;. SNOW; BENFORD, 1992) para investigar como os atores utilizam categorias de escala para "enquadrar" espacialmente problemas e soluções, incluir ou excluir determinados atores, legitimar projetos políticos, retrabalhar relações de poder e reunir processos políticos em torno de ordens de escala. Conceitualmente, esses "enquadramentos" são semelhantes aos esquemas de imagem de Lakoff e Johnson - são "esquemas de interpretação" socialmente compartilhados que permitem às pessoas compreenderem suas experiências (GOFFMAN, 1974, p. 21). Os processos de enquadramento, como narrativas, dão sentido aos acontecimentos e relações, e ao fazêlo funcionam tanto para organizar a experiência quanto para guiar a ação. Mais especificamente, os "quadros de ação coletiva" mobilizam apoio para a ação por meio da identificação de queixas e da atribuição de culpados, apresentando soluções e estratégias alternativas, e articulando justificativas para a ação coletiva para a busca de melhorias (BENFORD; SNOW, 2000). Como essa pesquisa deixa bem claro, enquadrar o contexto espacial e temporal é fundamental para o sucesso de qualquer projeto político. Consequentemente, enquadrar a escala e contestar quadros de escala é um importante objeto de investigação na dinâmica da política de escala.

A virtude das explicações que destaqueiéquenão caem na armadilha de presumir que a política enquadrada em termos de escala implica necessariamente a competição política entre escalas. Em vez disso, concentramse sobre a atribuição de - e na contestação sobre representações escalares dos eventos e relações sociais por parte de políticos, ativistas, empresas e funcionários, ultrapassando o tratamento limitado de escala como categoria analítica e situando-a no âmbito da experiência prática (KURTZ, 2002, p. 255). Eles demonstram que os atores usam categorias de escala não apenas para interpretar políticas de espaço, mas também para enquadrar e definir e, assim, constituir e organizar a vida social: "moldar um mapa mental ou visão de mundo particular que seja persuasivo e politicamente poderoso" (McCANN, 2003, p. 174). A política de escala está, em outras palavras, sempre ligada a projetos espaciais tenta cristalizar determinados arranjos socioespaciais na consciência e na prática com finalidades sociais, políticas ou culturais. As representações e práticas escalares são, portanto, parte de um conjunto mais amplo de empregos estratégicos do conhecimento geográfico relacionado a lutas política e de poder (TOAL, 2002).

\section{A variabilidade da "escalaridade" [scaleness]}

Tratar a escala como uma categoria da prática também nos alerta para níveis flutuantes de escala-ridade [scaleness] - a dimensão em que os atores pensam e agem em termos de escalas e em que as relações sociais e instituições são organizadas de acordo com preceitos de escala. Sob esse ponto de vista, os arranjos políticos e sociais não são continuamente "afixados" e "reafixados" em escalas específicas, como alega a tradição políticoeconômica. Modos alternativos de conceber e organizar a vida social, como as relações em rede, frequentemente coexistem ao lado de arranjos de escala, ou operam no lugar deles. Consequentemente, o grau em que a "escala" molda a vida social é uma questão em aberto cuja resposta deve ser buscada empiricamente, e não tratada como ponto de partida de qualquer investigação.

A sensibilidade para graus variáveis de escalaridade tem o potencial de aprofundar vários aspectos da investigação sobre a política de escala. 0 primeiro deles é que ajuda a evitar as descrições problemáticas do tipo "ou este ou aquele" que insistem em localizar a política espacial em ou entre escalas analiticamente prioritárias, uma conceituação da política de escala que é frequentemente encontrada, por exemplo, na literatura sobre o reescalonamento [rescaling] do Estado (MANSFIELD, 2005). Em segundo lugar, e com relação com o primeiro ponto, o reconhecimento de falhas e limitações da produção de escalas [scale-making] leva a uma teorização mais sofisticada da dinâmica da política de escala, porque nos impede de adotar uma visão excessivamente "escalar" do mundo. Isso nos ajuda a conceituar a escalaridade como um evento contingente que pode ou não ocorrer. Alertas para o fato de que os projetos de produção de escala podem falhar em produzir graus elevados de escalaridade, podemos começar a explorar tentativas fracassadas, enriquecendo assim a nossa compreensão da dinâmica da política de escala.

Emterceirolugar,conceituarescalaridadecomovariável e contingente abre espaço para uma investigação mais embasada do entrelaçamento entre práticas escalares e em rede, consciência e relações socioespaciais. Rede e escala tornaram-se, possivelmente, os modos espaciais 
dominantes de raciocínio tanto na cultura popular quanto na geografia humana nos últimos anos. Infelizmente, eles são frequentemente entendidos - como pelo artigo de Marston et al. (2005) - como categorias espaciais exclusivas ou contraditórias, tanto na teoria quanto em sua forma material, obstruindo assim tentativas de aprimorar as teorias sobre as relações socioespaciais. Mudar da análise para a prática e da fixidez para o dinamismo na nossa abordagem de redes e escalas promete facilitar uma investigação mais produtiva que ilumina projetos espaciais, processos de delimitação e ordenamento relacional e a constituição mútua de perspectivas e metáforas de escala e de rede (HEROD, 2003; BULKELEY, 2005).

Por último, reconhecer a variabilidade das práticas e consciência escalares fornece uma base mais sólida para a construção de análises processuais da política de escala. Apelos por abordagens processuais ou dialéticas da escala têm proliferado nos últimos anos (cf. HOWITT, 1993; 1998; 2002; HARVEY, 1996; SWYNGEDOUW, 1997b; 2004; MacLEOD; GOODWIN, 1999; BRENNER, 2000; 2004; MANSFIELD, 2001). Na verdade, pode-se dizer que "processo" é hoje uma das noções teóricas mais em voga na geografia humana. No entanto, descrições de processos muitas vezes são tornadas confusas pela presença de elementos teoricamente incompatíveis derivados do pensamento substancialista ${ }^{5}$. É possível identificar duas formas de substancialismo que surgem em análises ostensivamente processuais de geógrafos acerca da política de escala: a primeira confunde interação com relação e processo, ou seja, parte de substâncias reificadas - escalas ou soluções escalares de vários níveis (local, urbano, nacional, global etc.) - para então investigar as interações e mudanças de relação entre elas (lembre-se da discussão da estruturação de escala acima). Desse modo, "a relação não é independente do conceito de ser real; ela só pode adicionar modificações suplementares e externas a este último" (CASSIRER, 1953, p. 8); ou seja, as entidades precedem relações e processos.

$\mathrm{Na}$ segunda forma de substancialismo, mais sutil, os processos são conceituados como "algo com origem" - eles representam as realizações das substâncias (RESCHER, 1996, p. 44). Norbert Elias (1978) chamou de "redução de processo" essa tendência reificante de reformulação do fluxo constante de vida em forma de entidades. Seguindo Whorf (1956), ele observa que a redução de processo é incorporada às estruturas gramaticais de línguas ocidentais, cujas sentenças são compostas por dois elementos: substantivo e verbo. Isso dirige a atenção sobre as coisas em um estado de repouso e trata a mudança e a ação como um atributo adicional ou derivado. Ele ilustra essa afırmação com o exemplo a seguir:

\begin{abstract}
Às margens de um rio, vemos o fluxo infinito da água. Mas, para compreendê-lo conceitualmente, e comunicá-lo aos outros, não pensamos e dizemos 'Vejam, o fluxo infinito da água'; nós dizemos 'Vejam, como o fluxo do rio é rápido.' Nós dizemos 'o vento está soprando', como se o vento fosse realmente uma coisa em repouso que, em um determinado momento, começa a se mover e soprar. Nós falamos como se o vento fosse separado do seu soprar, como se pudesse existir um vento que não sopra. (ELIAS, 1978, p. 112)
\end{abstract}

Assim, os processos "que têm origem" são sempre decorrentes das coisas, substâncias ou atores, tanto na investigação quanto na explicação - "as entidades instigam processos ou processos são reificados como entidades" (JACKSON; NEXON, 1999).

Consideremos as duas declarações seguintes de um dos teóricos da escala mais resolutamente processuais: "As articulações de escala são profundamente reconfiguradas na luta perpétua do capital para controlar - local por meio de seu comando sobre o espaço" (SWYNGEDOUW, 1992b, p. 61) e "A escala [...] encarna um compromisso temporal, solidifica as relações de poder existentes, regula formas de cooperação e define relações competitivas e outras relações de poder" (SWYNGEDOUW, 1997b, p. 147).

Ambas as formulações priorizam "fazer coisas", esvaziando, assim, o suposto objetivo de uma análise processual de escala. Na primeira, o "capital" é identificado como a entidade geradora que impulsiona a reconfiguração de escala. Na segunda, os processos dinâmicos de ordenamento socioespacial são - como o exemplo de Elias da água fluindo em um rio - reificados e atribuídos a uma coisa chamada escala.

Para expandir o segundo ponto, considero revelador que Swyngedouw acredita que uma abordagem baseada em processo exige a rejeição de escalas ostensivamente pré-determinadas, como "global" e "local", como pontos de partida da investigação (1997b; 2004), mas não estende o questionamento para a validade de se investigar processos espaciais através das lentes da própria escala. Como Collinge (2005, p. 196) observa: "Em nenhum momento de sua discussão de 'glocalização', por exemplo, Swyngedouw considera o que seria necessário para demonstrar a existência do 'global', do 'local', ou de outras escalas, sugerindo que esses termos [...] podem ser considerados como dados". A implicação disso é clara. As escalas, como nações em muitas teorias do nacionalismo, são vistas como fatos ontológicos, as coisas que funcionam e fazem o mundo se manter coeso. Em suma, o substancialismo 
incorporado ao trabalho ostensivamente processual da escala decorre de uma conceituação de escala como uma categoria de análise, em vez de uma categoria de prática, de uma ênfase em escalas reificadas, em vez de na variabilidade da escalaridade. Na seção seguinte, eu forneço um esboço preliminar dos contornos de uma abordagem alternativa para a investigação política de escala em termos processuais.

\section{Processo e política de escala}

O ponto de partida de uma abordagem não substancialista de escala é a insistência na primazia dos processos e relações sobre as substâncias, entidades ou coisas. Meu argumento nesta seção é que uma abordagem processual totalmente embasada da escala, despojada de elementos substancialistas, exige uma reformulação do conceito de processos escalares para algo "sem origem" - isto é, uma mudança do tratamento desses processos como redutíveis a elementos nãoprocessuais para processos "sem sujeito" que "não consistem nos feitos de um ou mais agentes pessoais ou impessoais" (RESCHER, 1996, p. 45).

Muitos processos naturais e sociais, tais como a geada, a entropia ou um boato que se espalha são, ou podem ser proveitosamente tratados, como "sem origem" dessa maneira. É claro que a maioria dos processos sociais, tais como a propagação de um boato, geralmente são vistos como iniciados por alguém, constituídos por atores independentes. No entanto, como Jackson e Nexon (1999) notam:

\footnotetext{
Se estudarmos o boato como um processo com início definido, não estamos realmente estudando a "difusão" do boato. Em vez disso, estamos estudando como as interações de indivíduos mudam o rumor [...] Isso não é particularmente útil se queremos estudar como o processo, que é a difusão do boato, altera as relações que constituem o grupo - os laços entre os membros do grupo, a separação entre os membros do grupo e aqueles que estão fora dele, e assim por diante. (JACKSON; NEXON, 1999, p. 302, grifo do autor)
}

Da mesma forma, quando nos concentramos na escala em si como um processo com origem definida - como algo produzido por entidades substanciais, como indivíduos ou forças do capitalismo - deixamos de examinar a forma como o processo de sedimentação de configurações particulares de escala na consciência e na prática realinha relações socioespaciais, a forma como a delimitação horizontal e as epistemologias de ordenamento relacional específicas de um arranjo escalar emergente funcionam como um mecanismo gerador na implantação de determinados projetos sociais e políticos. Mas esses processos escalares e as alterações relacionais que geram são, eu insisto, exatamente as questões que uma abordagem processual da escala deveria procurar compreender.

Além disso, a cristalização ou institucionalização de configurações específicas podem também ser proveitosamente estudadas como eventos sem sujeito, contingentes, em vez de tratar as escalas materiais como produtossignificativos deatoressociaisespecíficos,como se costuma fazer. Para ser claro, isso não é negar que os indivíduos e as instituições desempenham um papel nos processos de escala. Mas não implica necessariamente que o surgimento de arranjos específicos de escala pode ser completamente reduzido a, ou adequadamente explicado por, ações de várias entidades, como faz o pensamento substancialista. Isso porque cada processo é em si um conjunto de outros processos que o compõem - "certas configurações de processos dão origem a novas configurações" (JACKSON; NEXON, 1999, p. 306). Assim, as configurações escalares são manifestações do agrupamento de delimitações socioespaciais mais básicas e processos de ordenamento relacional.

Isto significa que é necessário especificar quais epistemologias de delimitação e ordenamento relacional foram agrupadas, e identificar os mecanismos que geraram esse processo, a fim de fornecer uma explicação suficiente dos casos de transformação e sedimentação escalares. Minha ênfase nessa ligação é baseada na descrição processual perspicaz de Abbott (1995) sobre a formação de entidades. Invertendo a premissa padrão de que os limites são um correlato lógico de "coisificação" (os limites das coisas), ele argumenta que o agrupamento - a construção e a articulação dos limites a partir de locais rudimentares de diferença - produz "coisas" coerentes, similares a entidades, como escalas ou profissões acadêmicas (limites das coisas). A manobra processual da Abbott nos leva de volta para a epistemologia espacial, a categorização e a cognição metafórica, e para práticas representacionais de escala, tais como o enquadramento, a classificação e a narração, que produzem efeitos de escala. Histórias de escala, quadros e metáforas funcionam como mecanismos de convergência que nomeiam, agregam e delineiam os limites socioespaciais e as relações produzem epistemologias de "produção do mundo" e categorizações que consistem em "desmontar e montar, muitas vezes em conjunto" (GOODMAN, 1978, p. 8). Embora realizados por atores sociais, esses conjuntos de práticas são processos em curso que não são completamente controlados pelos atores que os empregam. 


\section{Conclusão}

A política de escala continua a ser uma das áreas mais vibrantes de pesquisa em geografia humana. Este ensaio não foi apresentado em uma tentativa de derrubar esse edifício. Em vez disso, argumentei que, apesar de uma recente virada construtivista, a literatura sobre a política de escala permanece apegada a uma conceituação problemática da escala como uma categoria importante de análise, o que facilitou a aceitação de vários pressupostos epistemológicos duvidosos sobre a política de escala e desviou a atenção das várias práticas de escala e dos locais socioespaciais dos atores sociais. Ademais, afirmo que distinguir os aspectos práticos da escala dos seus aspectos analíticos, e dirigir nosso foco de pesquisa para os primeiros, abre novos e frutíferos caminhos para a investigação e teorização da política de escala - caminhos esses que destacam a epistemologia, a categorização e a cognição; práticas e projetos escalares; e as possibilidades e o processo na política da escala. Espera-se que esta crítica e as futuras agendas de pesquisa oferecidas estimulem investigações produtivas sobre as dinâmicas mais amplas da política espacial.

\section{Agradecimentos}

Eu gostaria de agradecer a Leila Harris, Reece Jones, Robert Kaiser, Robert Sack e aos revisores anônimos da Progress in Human Geography por seus comentários.

\section{Notas}

1. Devo esse insight particular a um dos revisores anônimos.

2. Ver Howitt (2002) para uma exploração mais filosófica de incorporação e escala.

3. Ver Emirbayer (1997) para uma crítica mais embasada de substancialismo. 
Referências

ABBOTT, A. (1995) Things of boundaries. Social Research 62, 857-82.

AGNEW, J. (1987) Place and politics. London: Allen and Unwin

(1993) Representing space: space, scale and culture in social science. In: DUNCAN, J.; LEY, D., editors, Place/ culture/representation. London: Routledge, 251-71.

(1994) The territorial trap: the geographical assumptions of international relations theory. Review of International Political Economy 1, 53-80.

(1997) The dramaturgy of horizons: geographical scale in the 'reconstruction of Italy' by the new Italian political parties, 1992-1995. Political Geography 16, 99-121.

AMIN, A. (2002) Spatialities of globalization. Environment and Planning A 34, 385-89.

ANDREAS, P. (2004) The clandestine political economy of war and peace in Bosnia. International Studies Quarterly 48, $29-51$.

BARBER, B. (1995) Jihad vs. Mcworld. New York: Times Books.

BAX, M. (1997) Mass graves, stagnating identification, and violence: a case study in the local sources of 'the war' in Bosnia. Anthropological Quarterly 70, 11-19.

(2000) Warlords, priests and the politics of ethnic cleansing: a case study from rural Bosnia Hercegovina. Ethnic and Racial Studies 23, 16-36.

BENFORD, R.; SNOW, D.A. (2000) Framing processes and social movements: an overview and assessment. Annual Review of Sociology 26, 611-39.

BRENNER, N. (1997) State restructuring and the production of spatial scale: urban and regional planning in the Federal Republic of Germany: 1960-1990. Political Geography 16, 273-306.

(1998) Between fixity and motion: accumulation, territorial organization and the historical geography of spatial scales. Environment and Planning D 16, 459-81.

(1999) Beyond state-centrism? Space, territoriality, and geographical scale in globalization studies. Theory and Society $28,39-78$.

(2000) The urban question as a scale question: reflections on Henri Lefebvre, urban theory and the politics of scale. International Journal of Urban and Regional Research 24, 361-78.

$25,591-614$

(2001) The limits of scale? Methodological reflections on scalar structuration. Progress in Human Geography.

(2004) New state spaces. Oxford: Oxford University Press.

BROWN, M. (1995) Sex, scale and the 'new urban politics': HIV-prevention strategies from Yaletown, Vancouver. In: BELL, D.; VALENTINE G., editors. Mapping desire. New York: Routledge, 245-63.

BRUBAKER, R. (1996) Nationalism reframed. Cambridge: Cambridge University Press.

(2002) Ethnicity without groups. European Journal of Sociology 18, 163-89.

(2005) The 'diaspora' diaspora. Ethnic and Racial Studies 28, 1-19.

BRUBAKER, R.; COOPER, F. (2000) Beyond 'identity'. Theory and Society 29, 1-47.

BRUBAKER, R.; LOVEMAN, M.; STAMATOV, P. (2004) Ethnicity as cognition. Theory and Society 33, 31-64.

BULKELEY, H. (2005) Reconfiguring environmental governance: towards a politics of scales and networks. Political Geography 24, 875-902.

CALHOUN, C. (2003) Belonging in the cosmopolitan imaginary. Ethnicities 3, 531-53.

CASSIRER, E. (1953) Substance and function. New York: Dover. 
CASTREE, N. (2004) The geopolitics of nature. In: AGNEW, J., MITCHELL, K.; TOAL, G., editors. A companion to political geography. Oxford: Blackwell, 423-39.

COLLINGE, C. (2005) The differance between society and space: nested scales and the returns of spatial fetishism. Environment and Planning D: Society and Space 23, 189-206.

COX, K. (1996) Editorial: the difference that scale makes. Political Geography 15, 667-71.

CRESSWELL, T. (1997) Weeds, plagues and bodily secretions: a geographical interpretation of metaphors of displacement. Annals of the Association of American Geographers 87, 330-45.

DE CERTEAU, M. (1984) The practice of everyday life. Berkeley, CA: University of California Press.

DELANEY, D.; LEITNER, H. (1997) The political construction of scale. Political Geography 16, 93-97.

ELDEN, S. (2005) Missing the point: globalization, deterritorialization and the space of the world. Transactions of the Institute of British Geographers NS 30, 8-19.

ELIAS, N. (1978) What is sociology? New York: Columbia University Press.

EMIRBAYER, M. (1997) Manifesto for a relational sociology. American Journal of Sociology 103, 281-317.

FERGUSON, J.; GUPTA, A. (2002) Spatializing states: toward an ethnography of neoliberal governmentality. American Ethnologist 29, 981-1002.

FERME, M. (2004) Deterritorialized citizenship and the resonances of the Sierra Leonean state. In: POOLE, D., LEVENTHAL, R.; DAS, V., editors. Anthropology in the margins of the state. Santa Fe: School of American Research Press, $81-115$

FOUCAULT, M. (1991) Governmentality. In: BURCHELL, G., GORDEN, C.; MILLER, P., editors. The Foucault effect. Chicago: University of Chicago Press, 87-104.

FRIEDMAN, T. (2000) The Lexus and the olive tree. New York: Anchor Books.

GOFFMAN, E. (1974) Frame analysis. New York: Harper.

GOODMAN, N. (1978) Ways of worldmaking. Indianapolis: Hackett.

HAKLI, J. (2001) In the territory of knowledge: statecentered discourses and the construction of society. Progress in Human Geography 25, 403-22.

HARAWAY, D. (1991) Simians, cyborgs and women. London: Routledge.

HARVEY, D. (1982) Limits to capital. Chicago: University of Chicago Press.

(1996) Justice, nature and the geography of difference. Oxford: Blackwell.

HELD, D. (1995) Democracy and the global order. Cambridge: Polity Press.

HELLEINER, E. (2002) The making of national money. Ithaca, NY: Cornell University Press.

HEROD, A. (1997) Labor's spatial praxis and the geography of contract bargaining in the US east coast longshore industry. Political Geography 16, 145-69.

(2003) Scale: the local and the global. In: HOLLOWAY, S., Rice, S.; VALENTINE, G., editors. Key concepts in geography. London: Sage, 229-47.

HEROD, A.; WRIGHT, M. (2002) Placing scale: an introduction. In: HEROD, A.; WRIGHT, M., editors. Geographies of power. Oxford: Blackwell, 1-14.

HIRSCH, F. (2005) Empire of nations. Ithaca, NY: Cornell University Press.

HIRSCHFELD, L. (1996) Race in the making. Cambridge, MA: MIT Press.

HOBSBAWM, E.; RANGER, T. (1983) The invention of tradition. Cambridge: Cambridge University Press.

HOWITT, R. (1993) 'A world in a grain of sand': towards a reconceptualisation of geographical scale. Australian Geographer $24,33-44$. 
(1998) Scale as relation: musical metaphors of geographical scale. Area 30, 49-58.

(2002) Scale and the other: Levinas and geography. Geoforum 33, 299-313.

(2003) Scale. In: AGNEW, J., MITCHELL, K.; TOAL, G.,editors. A companion to political geography. Oxford: Blackwell, 138-57.

HUNTINGTON, S. (1996) Clash of civilizations and the remaking of world order. New York: Simon and Schuster.

JACKSON, P.T. and Nexon, D. (1999) Relations before states: substance, process and the study of world politics. European Journal of International Relations 5, 291-332.

JOHNSON, M. (1987) The body in the mind. Chicago: University of Chicago Press.

JOHNSON, N. (1995) Cast in stone: monuments, geography, and nationalism. Environment and Planning D 13, 51-65.

JONAS, A. (1994) Editorial: the scale politics of spatiality. Environment and Planning D 12, 257-64.

JONES, K. (1998) Scale as epistemology. Political Geography 17, 25-28.

JONES, M.; MACLEOD, G. (2004) Regional spaces, spaces of regionalism: territory, insurgent politics and the English question. Transactions of the Institute of British Geographers NS 29, 433-52.

KAISER, R.; NIKIFOROVA, E. (2006) Borderland spaces of identification and dis/location: multiscalar narratives and enactments of Seto identity and place in the Estonian/Russian borderlands. Ethnic and Racial Studies 25, 928-58.

KALYVAS, S. (2006) The logic of violence in civil war. Cambridge: Cambridge University Press.

KAPLAN, D. (1999) Territorial identities and geographic scale. In: KAPLAN, D.; HERB, G., editors. Nested identities. Lanham, MD: Rowman and Littlefield, 31-49.

KELLY, P. (1997) Globalization, power and the politics of scale in the Philippines. Geoforum 28, 151-71.

KURTZ, H. (2002) The politics of environmental justice as the politics of scale: St. James Parish, Louisiana, and the Shintech siting controversy. In: HEROD, A.; WRIGHT, M., editors. Geographies of power. Oxford: Blackwell, 249-73.

(2003) Scale frames and counter-scale frames: constructing the problem of environmental injustice. Political Geography 22, 887-916.

LAKOFF, G. (1987) Women, fire, and dangerous things. Chicago: University of Chicago Press.

LAKOFF, G. and Johnson, M. (1980) Metaphors we live by. Chicago: University of Chicago Press.

(1999) Philosophy in the flesh. New York: Basic Books.

LEITNER, H. (2004) The politics of scale and networks of spatial connectivity: transnational interurban networks and the rescaling of political governance in Europe. In: SHEPPARD, E.; MCMASTER, R., editors. Scale and geographic inquiry. Malden, MA: Blackwell, 236-55.

LEITNER, H.; PAVLIK, C.; SHEPPARD, E. (2002) Networks, governance, and the politics of scale: inter-urban networks and the European Union. In: HEROD, A. ; WRIGHT, M., editors. Geographies of power. Oxford: Blackwell, 274-303.

LEVINSON, S. (1996) Language and space. Annual Review of Anthropology 25, 353-82.

LEY, D. (2004) Transnational spaces and everyday lives. Transactions of the Institute of British Geographers NS 29, $151-64$.

MACLEOD, G.; GOODWIN, M. (1999) Reconstructing an urban and regional political economy: on the state, politics, scale, and explanation. Political Geography 18, 697-730.

MANN, M. (1986) The sources of social power, volume I. Cambridge: Cambridge University Press.

MANSFIELD, B. (2001) Thinking through scale: the role of state governance in globalizing North Pacific fisheries. Environment and Planning A 33, 1807-27.

(2005) Beyond rescaling: reintegrating the 'national' as a dimension of scalar relations. Progress in Human Geography 29, 458-73. 
MANSFIELD, B.; HAAS, J. (2006) Scale-framing of scientific uncertainty in controversy over the endangered Stellar sea lion. Environmental Politics 15, 78-94.

MARSTON, S. (2000) The social construction of scale. Progress in Human Geography 24, 219-42.

MARSTON, S.; JONES, J.P.; WOODWARD, K. (2005) Human geography without scale. Transactions of the Institute of British Geographers NS 30, 416-32.

MARTIN, D. (2003) 'Place-framing' as place making: constituting a neighborhood for organizing and activism. Annals of the Association of American Geographers 93, 730-50.

MCCANN, E. (2003) Framing space and time in the city: urban policy and the politics of spatial and temporal scale. Journal of Urban Affairs. 25, 159-78.

MCCARTHY, J. (2005) Scale, sovereignty, and strategy in environmental governance. Antipode 37, 731-53.

MCMASTER, R.; SHEPPARD, E. (2004) Introduction. In Sheppard, E. and McMaster, R., editors, Scale and geographic inquiry, Malden, MA: Blackwell, 1-22.

MUELLER, J. (2000) The banality of 'ethnic war'. International Security 25, 42-70.

OHMAE, K. (1995) The end of the nation-state. New York: Free Press.

PAASI, A. (1996) Territories, boundaries and consciousness. Chichester: Wiley. (2004) Place and region: through the prism of scale. Progress in Human Geography 28, 536-46.

Paasi, A.; NEWMAN, D. (1998) Fences and neighbors in the postmodern world: boundary narratives in political geography. Progress in Human Geography 22, 186-207.

PATRIARCA, S. (1996) Numbers and nationhood. Cambridge: Cambridge University Press.

PURCELL, M. (2003) Islands of practice and the Marston/ Brenner debate: toward a more synthetic critical human geography. Progress in Human Geography 27, 317-32.

RAENTO, P. and Brunn, S. (2005) Visualizing Finland: postage stamps as political messengers. Geografiska Annaler: Series B 87, 145-64.

RESCHER, N. (1996) Process metaphysics. Albany, NY: State University of New York Press.

RICOEUR, P. (1991) From text to action. Evanston, IL: Northwestern University Press.

SACK, R. (1980) Conceptions of space in social thought. Minneapolis, MN: University of Minnesota Press.

SAYER, A. (1985) The difference that space makes. In Gregory, D. and Urry, D., editors, Social relations and social structures. London: Macmillan, 49-66.

SCHATZKI, T. (2002) The site of the social. University Park, PA: Pennsylvania University Press.

SEARLE, J. (1995) The construction of social reality. New York: Free Press.

SILVERN, S. (1999) Scales of justice: law, American Indian treaty rights and political construction of scale. Political Geography 18, 639-68.

SMITH, N. (1984) Uneven development: nature, capital and the production of space. Oxford: Blackwell.

(1992) Contours of a spatialized politics: homeless vehicles and the production of geographical space. Social Text 33, 54-81.

(1993) Homeless/global: scaling places. In Bird, J., Curtis, B., Putnam, T., Robertson, G. and Tickner, L., editors, Mapping the futures, London: Routledge, 87-119.

(1995) Remaking scale: competition and cooperation in prenational and postnational Europe. In Eskelinen, $\mathrm{H}$. and Snickars, F., editors, Competitive European peripheries, New York: Springer, 59-74.

(1996) Spaces of vulnerability: the space of flows and the politics of scale. Critique of Anthropology 16, 63-77. (2000) Scale. In Johnston, R.J., Gregory, D., Pratt, G. and Watts, M., editors, The dictionary of human geography, 
Malden, MA: Blackwell, 724-27.

(2004) Scale bending and the fate of the national. In: SHEPPARD E.; MCMASTER, R., editors. Scale and geographic inquiry. Malden, MA: Blackwell, 192-212.

SMITH, R.G. (2003) World city actor-networks. Progress in Human Geography 27, 25-44.

SNOW, D.A.; BENFORD, R. (1992) Master frames and cycles of protest. In: MORRIS, A.D.; MUELLER, C.M., editors. Frontiers in social movement theory. New Haven, CT: Yale University Press, 133-55.

SNOW, D.A.; ROCHFORD, B.; WORDEN, S.; BENFORD, R. (1986) Frame alignment processes, micromobilization, and movement participation. American Journal of Sociology 51, 464-81.

SOMERS, M. (1994) The narrative constitution of identity: a relational and network approach. Theory and Society 23 , 605-49.

SWYNGEDOUW, E. (1992a) Territorial organization and the space/technology nexus. Transactions of the Institute of British Geographers NS 17, 417-33.

(1992b) The Mammon quest: glocalisation, interspatial competition and monetary order: the construction of new spatial scales. In: DUNFORD, M.; KAFKALAS, G., editors. Cities and regions in the new Europe. London: Belhaven Press, 39-67.

(1997a) Excluding the other: the production of scale and scaled politics. In: LEE, R.; WILLS, J., editors. Geographies of economies. London: Arnold, 167-76.

(1997b) Neither global nor local: 'glocalization' and the politics of scale. In: COX, K., editor. Spaces of globalization. New York: Guilford Press, 137-66.

(2000) Authoritarian governance, power and the politics of scale. Environment and Planning D 18,63-76.

(2004) Scaled geographies: nature, place and the politics of scale. In: Sheppard, E.; McMaster, R., editors. Scale and geographic inquiry. Malden, MA: Blackwell, 129-53.

TAYLOR, P. (1982) A materialist framework for political geography. Transactions of the Institute of British Geographers NS 7. 15-34. $151-62$

(1994) The state as a container: territoriality in the modern world system. Progress in Human Geography 18 , 1917-28.

(1996) Embedded statism and the social sciences: opening up to new spaces. Environment and Planning A 28,

(2004) Is there a network of cities? World-cities and the limitations of geographical scale analysis. In: SHEPPARD, E.; MCMASTER, R., editors. Scale and geographic inquiry. Malden, MA: Blackwell, 213-35.

TILLY, C. 1984: Big structures, large processes, huge comparisons. New York: Russell Sage.

(2002) Stories, identity and political change. Lanham, MA: Rowan and Littlefield.

TOAL, G. (2002) Theorizing practical geopolitical reasoning: the case of U.S. Bosnia policy in 1992. Political Geography $21,601-28$.

TORPEY, J. (2000) The invention of the passport. Cambridge: Cambridge University Press.

WALKER, R.B.J. (1993) Inside/outside. Cambridge: Cambridge University Press.

WHITE, H. (1987) The content of the form. Baltimore, MD: Johns Hopkins University Press.

WHORF, B. (1956) Language, thought and reality (edited by J. Carroll). Cambridge: MIT Press.

WINICHAKUL, T. (1994) Siam mapped. Oahu: University of Hawaii Press.

WITTGENSTEIN, L. (1953) Philosophical investigations. Oxford: Blackwell.

YEOH, B. (1996) Street-naming and nation-building: toponymic inscriptions of nationhood in Singapore. Area 28, 298307. 